\title{
Influence of Rapid Fluid Loading on Airway Structure and Function in Healthy Humans
}

\author{
MAILE L. CERIDON, PhD ${ }^{1}$, ERIC M. SNYDER, PhD ${ }^{2}$, NICHOLAS A. STROM, BS ${ }^{2}$, JUERG \\ TSCHIRREN, PhD $^{3}$, and BRUCE D. JOHNSON, PhD ${ }^{1}$ \\ ${ }^{1}$ Department of Physiology and Biomedical Engineering and Department of Internal Medicine, Mayo \\ Clinic, Rochester, MN \\ 2 Division of Cardiovascular Diseases, Mayo Clinic, Rochester, MN \\ ${ }^{3}$ Department of Electrical and Computer Engineering, University of lowa, lowa City, IA
}

\section{Abstract}

Background-The present study examined the influence of rapid intravenous fluid loading (RFL) on airway structure and pulmonary vascular volumes using computed tomography imaging and the subsequent impact on pulmonary function in healthy adults $(n=16)$.

Methods and Results-Total lung capacity $(\triangle \mathrm{TLC}=-6 \%)$, forced vital capacity $(\triangle \mathrm{FVC}=$ $-14 \%)$, and peak expiratory flow $(\triangle \mathrm{PEF}=-19 \%)$ decreased, and residual volume $(\Delta \mathrm{RV}=+38 \%)$ increased post-RFL $(P<.05)$. Airway luminal cross-sectional area $(\mathrm{CSA})$ decreased at the trachea, and at airway generation $3(P<.05)$, wall thickness changed minimally with a tendency for increasing in generation five $(P=.13)$. Baseline pulmonary function was positively associated with airway luminal CSA; however, this relationship deteriorated after RFL. Lung tissue volume and pulmonary vascular volumes increased $28 \%(P<.001)$ post-RFL, but did not fully account for the decline in TLC.

Conclusions-These data suggest that RFL results in obstructive/restrictive PF changes that are most likely related to structural changes in smaller airways or changes in extrapulmonary vascular beds.

\section{Keywords}

Pulmonary congestion; airway structure; airway function

\begin{abstract}
There are a number of conditions and disease states that influence lung fluid balance and can contribute to pulmonary congestion, including heart failure (HF). Patients with HF often develop unique pulmonary function changes that are both restrictive and obstructive in nature, and appear to correlate with disease severity as well as functional capacity. ${ }^{1}$ Causes of the reduced lung function in these patients are likely multifactorial and include changes in cardiac size, the development of pulmonary hypertension, as well as weakened respiratory muscles. ${ }^{2}$ Some investigators have suggested that excessive fluid, either in the form of blood volume or interstitial fluid, within the thoracic cavity may also be a factor in the observed declines in pulmonary function in HF patients. ${ }^{3}$ However, the specific alterations of fluid distribution within the thoracic cavity in those with pulmonary congestion remain controversial. ${ }^{1,4-6}$
\end{abstract}

Reprint requests: Dr. Bruce D. Johnson, Mayo Clinic College of Medicine, Department of Physiology and Biomedical Engineering, Mayo Clinic, Rochester, MN 55905. Tel: (507) 284-4441. Johnson. Bruce@ Mayo.edu. 
Rapid saline infusion in healthy humans has been used by a number of investigators to study the impact of fluid loading on the pulmonary system. ${ }^{7-13}$ This technique induces an isolated event of thoracic fluid volume overload, independent of other disease comorbidities, and results in transient changes in pulmonary function similar to that observed in the HF population. Although previous studies incorporating the fluid loading technique provide evidence for mild interstitial edema, the exact compartmentalization of volume in other intrathoracic areas (eg, within the pulmonary and bronchial vasculature) remains unclear. ${ }^{10,13}$ Pellegrino et al ${ }^{11}$ previously used rapid fluid loading in healthy humans and suggested that the fall in airway function may be linked in part to pulmonary and bronchial vascular engorgement or to space limitation within the thoracic cavity resulting in either impingement on the airway lumen or overall mechanical compression of the airways and other pulmonary structures.

The effect of thoracic fluid overload on airway structure is also likely to be nonhomogeneous because the compliance characteristics and response of the airways may differ relative to increasing airway generation and as the percentage of cartilage within the airway wall decreases. ${ }^{14,15}$ Greater cartilage content within the airway wall can limit the degree of airway narrowing and may play a role in the maintenance of airway patency, even when an individual is subjected to large fluid volume changes. Thus the impact of fluid loading on the airway wall and luminal diameters may be more marked as airway generation increases, although this has not been previously explored in a model of pulmonary congestion.

Previous studies have examined the interaction between airway structure and pulmonary function (eg, maximal flow rates, lung volumes, capacities) and have produced conflicting results. Many of these studies focused on changes occurring globally in the lung with fluid loading. ${ }^{7-9,11,12,16}$ The converse of this are studies that have examined changes in structure with fluid loading but only in single discrete cross-sections of airways of an unknown generation. ${ }^{10,17}$ Studies examining pulmonary function changes according to individual airway size have been conducted; however, these have been done primarily in asthmatics with specific application to the effects of altered bronchial smooth muscle tone rather than with fluid loading. ${ }^{18}$

To our knowledge, no previous studies have investigated the relationship between airway structure and function according to airway generation in a model of pulmonary congestion in humans. In addition, no studies have explored the impact of gross vascular volume changes on pulmonary function in a model of fluid overload. The focus of the present study, therefore, was to perform rapid fluid loading in healthy adults and to examine the impact of thoracic fluid volume overload on airway wall thickness and the resulting effects on airway luminal crosssectional area and pulmonary function.

Healthy individuals were used in this study to isolate the effects fluid overload in the absence of other physiologic adaptive mechanisms or disease comorbidities. We hypothesized that rapid fluid loading would result in a decrease in airway lumen diameter, leading to decrements in maximal lung volumes, functional capacities, and expiratory flows. Further, we hypothesized that changes in airway wall thickness would be more prominent in higher generation airways because of the lower cartilage content within the wall. X-ray computed tomography (CT) imaging techniques were used to allow visualization of the airway tree as an entire structure and to identify individual airways by branching generation. 


\section{Materials and Methods}

\section{Ethical Information}

The protocol was reviewed and approved by the Mayo Clinic Institutional Review Board and all participants provided informed written consent before participation. All aspects of the study complied with the standards set in the Declaration of Helsinki.

\section{Subjects}

Sixteen healthy nonsmoking adults with no history of cardio-pulmonary problems participated in the study. Individuals being treated for cardiovascular or pulmonary disorders were excluded from the study. Before the study, all participants underwent screening tests that included an incremental cycle ergometry test to exhaustion (to rule out cardiovascular abnormalities), pulmonary function tests, a complete blood count (to rule out anemia), and pregnancy testing for women of child-bearing potential.

\section{Pulmonary Function Measurements}

Participants underwent pulmonary function testing that consisted of simple spirometry preand post-rapid saline infusion. Measures obtained included forced vital capacity (FVC), forced expiratory volume in 1 second $\left(\mathrm{FEV}_{1}\right)$, inspiratory capacity (IC), maximal expiratory flows at $25 \%, 50 \%$, and $75 \%$ of the total $\mathrm{FVC}\left(\mathrm{FEF}_{25}, \mathrm{FEF}_{50}, \mathrm{FEF}_{75}\right.$, respectively), mean maximal expiratory flows between $25 \%$ and $75 \%$ of $\mathrm{FVC}\left(\mathrm{FEF}_{25-75}\right)$, and peak expiratory flow (PEF). Spirometry measures were collected in accordance with American Thoracic Society standards. 19

\section{Measurements of Cardiac Output, Diffusing Capacity, and Capillary Blood Volume}

Rebreathe techniques measuring the simultaneous disappearance of acetylene, carbon monoxide $(\mathrm{CO})$ and of nitric oxide (NO) were used to determine cardiac output $(\mathrm{Q})$, lung membrane diffusing capacity $\left(\mathrm{D}_{\mathrm{M}}\right)$ and pulmonary capillary blood volume $\left(\mathrm{V}_{\mathrm{C}}\right)$ as described by Tamhane et al. ${ }^{20}$

Briefly, A 5-L rebreathe bag was filled with $0.3 \%$ carbon monoxide $\left(\mathrm{C}^{18} \mathrm{O}\right), 40$ parts per million NO (diluted immediately before the test in the bag from an 800 parts per million gas mixture), $35 \% \mathrm{O}_{2}, 9 \% \mathrm{He}$. Gases were sampled by mass spectrometer (Perkin-Elmer, 1100, Waltham, $\mathrm{MA}$ ) and NO analyzer (Sievers Instruments, Boulder, $\mathrm{CO}$ ); analysis was performed using a custom software package. ${ }^{13,20}$ The volume of gas used to fill the rebreathe bag was determined by the tidal volume of the subject. At the end of a normal expiration (end-expiratory lung volume), the subjects were switched into the rebreathe bag and instructed to nearly empty the bag with each breath for 10 consecutive breaths. The respiratory rate during the rebreathe maneuver was controlled with a metronome at a rate of 32 breaths/min. After each diffusing capacity maneuver, the rebreathe bag was emptied with a suction device and refilled immediately before the next maneuver.

Calculations of DM and $\mathrm{VC}$ were based on the disappearance of $\mathrm{CO}$ and $\mathrm{NO}$ during rebreathing and determined according to the following Roughton-Forster equation: $:{ }^{21} 1 / \mathrm{DLCO}=1 / \mathrm{DMCO}$ $+1 /(\theta \mathrm{CO} \times \mathrm{Vc})$, where DLCO is the diffusing capacity of the lung for $\mathrm{CO}$, DMCO is the diffusing capacity of the alveolar capillary membrane for $\mathrm{CO}$, and $\theta \mathrm{CO}$ is the rate of reaction between $\mathrm{CO}$ and hemoglobin $(\mathrm{Hgb})$. The term $1 / \theta \mathrm{CO}$ is defined as the following $1 / \theta \mathrm{CO}=(0.73$ $+0.058 \mathrm{PAO} 2) \times 14.6 / \mathrm{Hgb}$, where $\mathrm{PAO} 2$ is the partial pressure of $\mathrm{O} 2$ in the alveoli. DMCO is determined from the ratio $\mathrm{DLNO} / \mathrm{DMCO}=\mathrm{DMNO} / \mathrm{DMCO}=\alpha \mathrm{NO} / \alpha \mathrm{CO} \sqrt{ }(\mathrm{MWCO} / \mathrm{MWNO})$ where DMNO is the diffusing capacity of the alveolar capillary membrane for $\mathrm{NO}, \alpha \mathrm{CO}$ and $\alpha \mathrm{NO}$ are the Bunsen solubility coefficients in tissue of $\mathrm{CO}$ and NO respectively, MWCO and MWNO are the molecular weights of CO and NO respectively, and yields a value theoretical 
value of $1.93 .^{22}$ Additionally, because each maneuver is performed with less than 30 seconds of rebreathing, the recirculation of acetylene, $\mathrm{CO}$, and $\mathrm{NO}$ are considered to be negligible. ${ }^{23}$ For our laboratory, the coefficients of variation are $7.2 \%$ for $\mathrm{D}_{\mathrm{M}}$ and $6.4 \%$ for $\mathrm{V}_{\mathrm{C}}$.

Rebreathe maneuvers were performed in triplicate on each subject before and after the saline infusion. Residual volume (RV) was also determined by means of helium dilution.

\section{Rapid Fluid Loading}

Rapid fluid loading was achieved by means of a rapid intravenous saline infusion. Subjects reported to the clinical research unit (National Institutes of Health-sponsored core research facility) on the morning of their study between the hours of 0700 and 0900 in a fasting state. An 18-gauge venous catheter was inserted into a prominent antecubital vein. Baseline measures of pulmonary function and lung structure from CT scans were obtained before the infusion. Saline ( $0.9 \%$ isotonic solution) was then infused intravenously ( $30 \mathrm{~mL} / \mathrm{kg}$ over 15 to 20 minutes) while the subject was on the $\mathrm{CT}$ bed to optimize timing and position for postsaline CT measures. During the saline infusion, oxygen saturation, blood pressure, heart rate, and physical symptoms were continuously monitored and recorded every 2 minutes. After the infusion, repeat assessment of pulmonary function and CT-based imaging of the total lung was performed. Postsaline CT structure and pulmonary function measures were performed within 15 minutes of completion of the infusion.

\section{CT-based Measurements of Lung Anatomy}

All CT scans were performed on the same single detector scanner (GE LiteSpeed spiral CT scanner, GE Healthcare, Waukesha, WI) with images acquired at scanner settings of $120 \mathrm{kVp}$ tube voltage and $100 \mathrm{mAs}$ exposure. Before the baseline scan, a scout scan was performed to determine the location and size of the lungs. Marks were placed on the skin of the subject to indicate the anatomical location of the start of the scan, and the table height was set during the first baseline scan and was not altered until after the postsaline scan data were collected. The number of slices of the total thoracic images was maintained during scanning data collection to retain consistency of the reconstructed images. All scans were reconstructed to a $1.25-\mathrm{mm}$ slice thickness with a 0.6-mm overlap. In-plane field of view was set for each individual to include the entire lung and a $512 \times 512$ matrix applied, yielding an average in plane pixel size of $0.68 \mathrm{~mm}$ per side. Total effective dose to the subject was estimated at $781 \mathrm{mrad}$ for males and $1167 \mathrm{mrad}$ for females.

\section{Normalization of Lung Volumes during CT Scanning}

Subjects were asked to breathe on a mouthpiece with a pneumotachometer connected to a portable computer with custom analysis software that provided accurate lung volume measures while scanning. During the scans, investigators observed the breathing pattern of each subject with a computer display from the pneumotachometer and coached the subjects to the desired lung volume for breath-hold during imaging. The absence of pressure spikes in the recorded data from the pneumotachometer pressure transducer ensured that subjects were not performing a Valsalva maneuver during the breath-holds. Baseline scans were conducted with each subject breath-holding at end-expiratory lung volume and at total lung capacity (TLC). Postsaline scans were performed at end-inspiratory lung volume, a volume flanked on either side by those collected in the baselines scans. Structural and water content measurements were compared with values corrected for the small difference in lung inflation pre- and postsaline loading. Briefly, a line of interpolation (based on lung inflation volume) was constructed from the 2 baseline scans for each measurement, for each individual. The lung volume obtained from the postsaline end-inspiratory lung volume scan was then used to compare postsaline measurements to the corresponding presaline value lying along the line of interpolation. Because there are variable decreases in the full inflation volume postfluid loading, it is 
impossible to have matched lung volumes at TLC after the saline infusion. ${ }^{24}$ The described method was used for relative matching of lung volumes ensuring accurate comparisons, while minimizing the number of scans and amount of radiation exposure to the subjects. Previous work investigating the effect of inflation volume on lung composition have shown that this relationship can be assumed to be linear over the range of lung volumes used for the present study. ${ }^{25,26}$

\section{CT Image Analysis-Airway Segmentation}

The CT images were loaded into Pulmonary Workstation (PW), pulmonary analysis package developed by VIDA Diagnostics (Iowa City, IA) designed for use with 3-dimensional (3D) images of the lung. Overlapping CT image slices allowed for reconstruction of the airway tree, multidimensional CT image display, and measurement of the branching airways. ${ }^{27}$

Automated analysis algorithms segment volumes, calculate the centerline of the vessels of the airway tree, and subsequently measure airway vessel lumen diameter, airway wall thickness, and outer vessel diameter at any specified spatial position down the airway tree. Further detail of these measurement algorithms have been described previously. ${ }^{28-31}$ Briefly, each element of the 3D image set is analyzed to identify, based on the inherent contrast intensity in Hounsfield units (HU), the voxels that comprise the airway tree. These voxels are grouped into a single airway segmentation. The inner and outer boundaries of the airway wall are determined by optimal surface detection algorithms, applying cost function minimization techniques to individual voxel elements propagating down the stacked transverse plane images of the entire collected 3D image set. The centerline of an airway is computed as a point at which diameter lines converge and is equidistant from the inside airway wall along any given diameter measurement. Centerpoints are concatenated to form centerlines along an airway and a skeleton of the branches of the entire airway tree is created based on these interconnected centerlines. The points of intersection for the centerlines are also labeled as branch points and numbered in succession in the skeletonization process. Craniocaudal analysis applies labels the airways based on an anatomical template giving each airway a unique segment identification as well as a generation number according to Weibel designation with the trachea numbered as zero, and an increment of one applied at each branch point. Each airway is also divided in length into thirds from the parent to child branch points.

Structural measurements of interest include the airway luminal area (cross-sectional, $\mathrm{mm}^{2}$ ), airway wall thickness $(\mathrm{mm})$, and total airway area (cross-sectional, airway luminal area + airway wall area, $\mathrm{mm}^{2}$ ). Dimensions of the airways are measured from the centerline to the airway edge in each slice of the 3D image set. Reported dimensions represent the average of all the measurements collected along the middle third of each individual airway segment.

Airway measurements were separated by generation beginning with the trachea (generation 0 ) and continuing down the airway tree for as many branching generations as could be resolved in each CT image. ${ }^{32}$ Because the software did not allow 2 scans to be simultaneously evaluated and the differences directly compared, a technician was used to visually examine each pair of scans. With the PW segmentation algorithms, each airway is given a unique identifier number and this identifier number was noted for each airway in all scans for a single individual. The role of the technician was only to ensure that an airway obtained in 1 scan was exactly matched to the same airway in another scan. The measured dimensions output from the PW software were then compared on an airway-by-airway basis. This was done to ensure that each airway was compared with itself and that any changes were reflective of the individual responses in each airway. Measurements on airways were grouped by branching generation and averaged for the airways of that given branching order, yielding a single averaged value per generation per scan per individual. 


\section{Lung Density, Tissue Volume, and Vascular Segmentation Analysis Using CT Imaging}

The CT images were loaded into additional specialized analysis software known as pulmonary analysis software suite (VIDA Diagnostics, Iowa City, IA) also designed for use with 3D reconstructions of the lung. Lung tissue was separated from surrounding structures and the mediastinum as described previously. ${ }^{13,24}$ Lung voxels at $-1000 \mathrm{HU}$ or lower are considered to be air only ( $0 \%$ tissue). Lung voxels at $65 \mathrm{HU}$ (value of blood) or higher are considered to be $100 \%$ tissue. HU values in between these 2 points are assigned a "percent tissue" value that follows a linear relationship at the lung volumes used in the present study. ${ }^{25}$ The volume of each individual voxel was then multiplied with its respective percent tissue value to obtain a measure of density and the volume of tissue contained within each voxel analyzed. These values were summed up within the lung field to obtain a representative tissue. Lung tissue volume and lung density data obtained from baseline images were plotted against lung volume and used for linear interpolation to obtain data against which postfluid loading images were compared.

Vascular segmentation was conducted using an additional automated algorithm within the pulmonary analysis software suite software as described previously. ${ }^{33}$ Briefly, vessels approximately $5 \mathrm{~mm}$ in diameter and smaller were identified in 3D by applying a line filter consisting of a Hessian matrix. Eigenvalues of the matrix were computed at each voxel position within the lung. High-magnitude eigenvalues of the Hessian matrix and their associated image volumes were marked as a "vessel piece" within the algorithm at various size scales. "Vessel pieces" were then concatenated to obtain the final segmentation. It should be noted that the final segmentation does not take into account the vascular volumes of vessels $5 \mathrm{~mm}$ in diameter or larger, including that of the greater vessels. Nor does the segmentation take into account vessels smaller than what can accurately be resolved spatially for a given voxel size and reconstruction kernel.

Vascular volumes were then determined using the image analysis software ANALYZE ${ }^{34}$ to calculate the number of voxels within the vascular segmentation and the volume represented by that segmentation. Lung vascular volumes between the baseline condition and the postsaline loading condition were compared with values corrected for the small difference in lung inflation pre- and postsaline loading as described previously for structural and water content measurements of the lung. All vascular volumes are reported as comparative values and represent the change in detected vascular volume that occurred as a result of the rapid fluid loading. Values are presented as a percent of the obtained baseline quantity for each individual.

\section{Data Analysis}

All statistical comparisons were made using the SPSS statistical software package (Version 12.0, Chicago, IL). The differences in the physiologic parameters, pulmonary function, and airway structural characteristics at baseline and postsaline were compared using repeated measures Analysis of variance with an alpha level of 0.05 to determine significance. Correlation and covariance were determined using parametric testing methods with Pearson mean correlation coefficients. Values are reported as mean $\pm \mathrm{SD}$.

\section{Results \\ Subject Characteristics}

Sixteen healthy adults (11 males, 5 females) meeting the inclusion and exclusion criteria participated in the study as shown in Table 1. 


\section{Physiologic Responses to Rapid Fluid Loading}

Subject monitoring measurements are summarized in Table 2. All subjects tolerated the rapid fluid loading with a mean infusion volume of $2201 \pm 344 \mathrm{~mL}$ over an average period of 20.5 \pm 2.1 minutes. The most common symptom reported was chest tightness that averaged $1.1 \pm 1.0$ on a scale from 0 to 4 . Subjects demonstrated significant increases in heart rate $(60 \pm 8$ to 73 \pm 14 beats/min, $P<.001)$, systolic blood pressure $(112 \pm 9$ to $119 \pm 10 \mathrm{~mm} \mathrm{Hg}, P<.05)$, and $\mathrm{Q}(4.1 \pm 0.8$ to $5.2 \pm 1.2 \mathrm{~L} / \mathrm{min}, P<.001)$ from baseline to postfluid loading condition; however, the arterial $\mathrm{O}_{2}$ saturation remained unchanged between the 2 conditions (oxygen saturation, $97 \pm 1 \%$ to $98 \pm 2 \%, P>.05$ ). Additionally, diastolic blood pressure, mean arterial pressure, and stroke volume remained unchanged $(P>.05)$ between the baseline and postfluid loading condition.

\section{Pulmonary Function with Rapid Fluid Loading}

Marked changes were observed in lung function in the post-rapid fluid loading condition (Table 3). There was a significant fall in TLC and a rise in RV along with significant declines in FVC (from $5.2 \pm 1.0 \mathrm{~L}$ at baseline to $4.5 \pm 1.1 \mathrm{~L}_{\text {postsaline), }} \mathrm{FEV}_{1}$ (from $4.2 \pm 0.9 \mathrm{~L}$ at baseline to $3.6 \pm 0.9 \mathrm{~L}$ postfluid loading), $\mathrm{PEF}$ (from $9.3 \pm 1.8 \mathrm{~L} / \mathrm{s}$ at baseline to $7.4 \pm 1.7 \mathrm{~L} / \mathrm{s}$ postsaline), and $\mathrm{FEF}_{25}, \mathrm{FEF}_{50}, \mathrm{FEF}_{75}$, and $\mathrm{FEF}_{25-75},(P<.01$ for all values) from baseline measurements (Fig. 1, 2).

\section{Measurements of $D_{L C O}, D_{M}$, and $V_{C}$}

Measures of $D_{L C O}, D_{M}$, and $V_{C}$ partially gauge the fluid distribution within the lungs where $\mathrm{D}_{\mathrm{LCO}}$ is a measure of the combined effects of $\mathrm{D}_{\mathrm{M}}$ (representative of changes in interstitial fluid) and $\mathrm{V}_{\mathrm{C}}$ (representative of changes in capillary blood volume in contact with alveolar structures). In the present study, there was a slight decrease in $\mathrm{D}_{M}$ ( $-9 \%$ relative to baseline, $P<.02)$ and an increase in $\mathrm{V}_{\mathrm{C}}(+42 \%$ relative to baseline, $P<.02)$ with rapid fluid loading (Table 4). No direct correlations were observed between $\mathrm{D}_{\mathrm{LCO}}$ and $\mathrm{V}_{\mathrm{C}}, \mathrm{D}_{\mathrm{M}}$, or $\mathrm{D}_{\mathrm{M}} / \mathrm{V}_{\mathrm{C}}$. A relationship was observed between $\mathrm{D}_{\mathrm{LCO}}$ and PEF in the baseline condition $(r=0.58, P<.02)$ as well as in the postsaline condition $(r=0.50, P<.05)$, but not in the calculated percent changes in these variables $(P>.05)$.

\section{CT Imaging: Vascular Changes}

Rapid fluid loading induced significant increases in the representative lung tissue volume from a baseline value of $819 \pm 160 \mathrm{~mL}$ to a postfluid loading value of $898 \pm 149 \mathrm{~mL}(P<.01)$. As a subset of this tissue volume, the measured volume of the segmented vascular structure also increased from a baseline value of $113 \pm 26 \mathrm{~mL}$ to a postfluid loading value of $125 \pm 26 \mathrm{~mL}$ $(P<.001)$. This postloading measurement represents an average vascular volume increase of 9\% $(P<.001)$ (Fig. 3).

No direct relationships between lung tissue volume and $\mathrm{V}_{\mathrm{C}}, \mathrm{D}_{\mathrm{M}}$, or $\mathrm{D}_{\mathrm{M}} / \mathrm{V}_{\mathrm{C}}$ were observed. The percent change in lung tissue volume tended to be negatively associated with the percent change in $\mathrm{D}_{\mathrm{M}} / \mathrm{V}_{\mathrm{C}}$; however, this relationship did not reach statistical significance $(r=-0.45$, $P=.079)$.

\section{CT Imaging: Airway Changes}

Sixteen subjects had clearly defined total airway resolution in both baseline and postfluid loading images for comparison from the trachea (generation 0 ) to generation 4of the branching airways. Ten subjects had airway resolution in both baseline and postfluid loading images to generation 5 . Beyond airway generation 5 , there were less than 10 subjects that showed clearly delineated airways in both baseline and postfluid loading analysis of the CT scans using the PW software. As such, additional generations are not reported. The number of total airways 
detected at each generation was 16, 32, 64, 130, 119, and 49 at generations $0,1,2,3,4$, and 5, respectively. ${ }^{13}$

Airway luminal area was not significantly altered by rapid fluid loading at generations $1(-2$ $\pm 7 \%$ relative to baseline, $P>.05), 2(-4 \pm 12 \%$ relative to baseline, $P>.05), 4(-4 \pm 13 \%$ relative to baseline, $P>.05)$, and $5(0 \pm 8 \%$ relative to baseline, $P>.05)$; however, airway luminal area was significantly decreased at the trachea (generation $0,-4 \%$ relative to baseline, $P<.04)$ and at generation $3(-5 \pm 8 \%$ relative to baseline, $P<.02)$. Total airway area was not significantly altered by rapid fluid loading at generations $1(-1 \pm 6 \%$ relative to baseline, $P>$. $05), 2(-3 \pm 10 \%$ relative to baseline, $P>.05), 4(-2 \pm 10 \%$ relative to baseline, $P>.05)$, and $5(+1 \pm 7 \%$ relative to baseline, $P>.05)$; however, total airway area was significantly reduced at the trachea $(-4 \pm 5 \%$ relative to baseline, $P<.01)$ and at generation $3(-2 \pm 5 \%$ relative to baseline, $P<.05)$.

Airway wall thickness was not significantly altered by rapid fluid loading at the trachea $(-1 \pm$ $10 \%$ relative to baseline, $P>.05)$, or at generations $1(-1 \pm 6 \%$ relative to baseline, $P>.05)$, $2(+2 \pm 43 \%$ relative to baseline, $P>.05), 3(0 \pm 34 \%$ relative to baseline, $P>.05)$, and $4(-2$ $\pm 16 \%$ relative to baseline, $P>.05$ ). At generation 5, the change in airway wall thickness tended to increase $(+13 \pm 33 \%$ relative to baseline, $P=.13)$.

\section{Structure-Function Relationships}

Before fluid loading, there were good relationships between lung function measures and airway luminal volumes (Fig. 4A); however, after loading, these relationships deteriorated substantially. This occurred despite relatively small changes in the average airway luminal diameters and cross-sectional areas, as well as average wall thicknesses. However, there was large variation in the observed airway structural changes across subjects with some demonstrating more marked reductions in airway luminal areas and increases in wall thickness. For example, at generation 5, the change in luminal CSA ranged from $-8.8 \%$ to $+17.9 \%$ across subjects and the change in wall thickness ranged from $-20.8 \%$ to $+99.8 \%$. Interestingly, however, there were no strong correlations observed between the changes in airway luminal areas and the changes in lung function. In addition, taking into account minimal or average luminal areas for a given airway generation did not improve these relationships. Figure 4B shows that the previously observed strong relationship between lung function and luminal area deteriorates to a marginal relationship, suggesting a heterogeneous change in luminal areas with saline loading.

\section{Discussion}

In the present study, we sought to determine the impact of rapid fluid loading on airway structure according to airway generation. We further sought to determine how changes in each generation subsequently influenced pulmonary function in healthy adults. Strengths of the study are the comprehensive quantification of the entire length of airways, quantification of multiple airways for a given generation, as well as examining multiple generations to explore the relationship between airway structure and function, rather than categorizing single airways within a given CT slice based on a discrete cross-sectional diameter. Previous studies investigated changes in airway structure categorized by airway size; however, airway size is variable and dependent on the size of an individual. In addition, we report novel data using noncontrast CT imaging techniques to quantify changes in pulmonary vascular volume to determine the influence rapid fluid loading on functional changes in the lungs.

The rapid infusion of saline resulted in mild interstitial edema, as evidenced by a slight decrease in $\mathrm{D}_{\mathrm{M}}$. Declines in TLC and in maximal expiratory flows and a rise in $\mathrm{RV}$ were consistent with both restrictive and obstructive changes. There were small changes in airway luminal areas 
from the trachea through airway generation 5. Airway wall thickness on average demonstrated minimal changes; however, with tendency for an increase in generation 5 (Fig. 5). Increases in vascular volumes (large arteries/veins and pulmonary capillaries) coincided with the declines in TLC. Despite large variation across subjects in airway luminal changes, measures of maximal expiratory flow were generally not associated with the changes in the average minimal luminal areas for the generations of airways reported. These data suggest that pulmonary function changes associated with rapid fluid loading were not primarily determined by narrowing of the larger airways. Functional changes may be related to changes in smaller airways or to changes in fluid compartments (eg, heart and great vessels, abdomen) not quantified in this study.

\section{Physiologic Effects of Fluid Overload}

Previous studies with rapid fluid loading of healthy individuals demonstrated reduced pulmonary function ${ }^{11,12,16}$ with the postloading functional tests exhibiting both restrictive and obstructive pulmonary abnormalities. Decreases in lung function may be related to edema in the airway wall that could cause subsequent tissue encroachment on the airway lumen, thereby influencing expiratory flow. ${ }^{11,12}$ Another theory for these functional declines is the narrowing of airways by engorgement of the thoracic vasculature. ${ }^{11}$

One vascular bed specifically implicated is the bronchial circulation. ${ }^{6,11}$ This circulatory bed lies near the bronchial wall and has the potential to swell and become edematous, potentially impinging on the airway lumen. Previous work by Cabanes et $\mathrm{al}^{6}$ demonstrated improved exercise performance with inhaled methoxamine, an $\alpha 1$-specific adrenergic agonist known to constrict the bronchial circulation, in HF subjects with exertional dyspnea and suggested that an engorged bronchial circulation may play a role in the pulmonary congestion associated with HF. ${ }^{6}$ Pellegrino and colleagues ${ }^{11}$ using rapidly infused saline in healthy adults also, observed functional changes consistent with mild airflow obstruction, pulmonary vascular congestion, or mild pulmonary interstitial edema. ${ }^{11}$ These authors also implied that the observed changes may be resultant of tissue encroachment on the lumen of bronchial structures.

\section{Intrathoracic Fluid Distribution and Pulmonary Function with Rapid Fluid Loading}

An average 400-mL drop in TLC was observed with rapid fluid loading in the present study; however, only a fraction of this change in TLC could be accounted for from measured thoracic fluid changes. Increases in lung tissue volume (average increase of $79 \mathrm{~mL}$ ), a measure that reflects all fluid changes within the lung, only partially accounts for the total fall in TLC. Much of the increase in the lung tissue volume (50\% to $60 \%$ of the observed increase in lung tissue volume) is accounted for by increases in $\mathrm{V}_{\mathrm{C}}$ (average increase of $32 \mathrm{~mL}$ ) and in the segmented vascular volume (average increase of $12 \mathrm{~mL}$ ). The remainder of the increase in tissue volume is likely from an increase of fluid in the interstitial space, suggested by the fall in $D_{M}$ that occurred despite a rise in $\mathrm{V}_{\mathrm{C}}{ }^{20}$

Given this simple accounting for the increase in lung tissue volume, it remains unclear where the additional volume displacement reflected in the decline in TLC is occurring. Additional fluid may be residing within the thorax but outside of the lungs, possibly in the heart and great vessels or an expansion of the abdomen may serve to limit the diaphragm's ability to descend and thus encroach on the thoracic space available to lung capacity.

Also observed was a parallel shift in the maximal expiratory flow values postloading, with little change in the $\mathrm{FEV}_{1} / \mathrm{FVC}$ ratio, suggesting the functional differences are restrictive in nature. However, work by Hyatt ${ }^{35}$ and others have noted similar parallel shifts of the maximum expiratory flow curve with mild, induced bronchospasm in asthmatic subjects. Thus such a parallel shift is not limited to only restrictive changes occurring in the lung. The observed rise 
in $\mathrm{RV}$ is consistent with some airway obstruction and would imply some airway impingement caused from increases in interstitial fluid, swelling of the bronchial wall in smaller airways, or from vascular expansion.

\section{Space Limitations and the Structure-function Relationship}

The nearly parallel fall in the maximal expiratory flow curve was observed with the percent reduction tending to be slightly greater at higher lung volumes. Although this would suggest that largest airways are primarily involved, only small changes were observed in the average luminal cross-sectional areas of the trachea (generation 0 ) and airway generation 3; with minimal changes observed in the other generations reported. Although these changes might contribute to the reduction in airflow, the relatively strong relationship between airway diameter and lung function preloading was not evident postloading, making it doubtful that the fall in lung function was dependent only on changes in these airways. This may be expected as the cartilage content within the wall falls with each subsequent airway generation, making higher generation airways more compliant and thus more susceptible to luminal impingement from expansion of the bronchial circulation or to mechanical compression of the airway arising from competition for space within the thoracic cavity.

Olson et $\mathrm{al}^{4}$ showed that cardiac enlargement relates to drops in lung function (specifically TLC, FVC, and $\mathrm{FEV}_{1}$ ), lending to the idea that space limitations may be contributing to the restrictive lung changes seen with the rapid infusion of saline in these healthy individuals. In the case of rapid saline infusion, excess fluid within the thoracic cavity, and specifically within intrathoracic vascular compartments, plays a part in space limitations for the lung. Studies by Muir ${ }^{16}$ reported similar functional declines in fluid-loaded subjects and also demonstrated by hemodilution that much of the infused volume remains intravascular. This supports the idea that thoracic space limitation may be a contributing factor.

\section{Observed Morphology with Rapid Fluid Loading}

Morphologic studies using rapid saline infusion techniques to determine structural effects of fluid overload have previously been conducted in both animal and human models. Brown et $\mathrm{al}^{17}$ conducted studies in dogs using CT imaging and have shown increases in airway wall thickness, decreases in airway caliber occurring with increases in pulmonary arterial, and pulmonary capillary wedge pressures in response to fluid loading. However, it was suggested swelling of the bronchial wall to the point of impingement on the airway lumen was unlikely given that the aggressive fluid loading protocol produced only moderate morphologic changes. These authors concluded that bronchovascular congestion was unlikely to be the primary cause of obstruction in the airways in fluid volume overload.

King et $\mathrm{al}^{10}$ also studied morphologic changes in response to fluid loading using similar CT imaging techniques in a small number of normal and aquaporin-null human subjects. In control subjects, these authors reported significant increases in airway wall thickness, peribronchial cuffing consistent with early peribronchial edema, and mild airway obstruction, suggesting water flux into the airway wall can reduce airway lumen diameter in normal individuals. ${ }^{10}$

Previously observed functional changes are consistent with the present findings. ${ }^{8,11,16}$ However, the results on the structural morphology of the bronchial wall initially appear to be in contrast to this study in that other investigators observed greater increases in airway wall thickness. ${ }^{10,17}$ The discrepancy between these results may be related to methodology. In the studies by Brown ${ }^{17}$ and by King, ${ }^{10}$ fluid was infused at a slightly more aggressive rate than that of the present study. Additionally, the targeted airway size and the method for quantifying airway dimensions also differed from that in the study by King et al. ${ }^{10}$ 
A strength of the present study is that scans of the entire lung were collected allowing for reconstruction and comparison of the entire airway tree. In contrast, King et al ${ }^{10}$ analyzed scans traversing only 5 to $6 \mathrm{~cm}$ in the craniocaudal direction and with a smaller in-plane field of view. This partial section of the lung is smaller than that of the present study allowing for decreased in-plane pixel size and a higher corresponding spatial resolution resulting in the ability to measure smaller airways.

This difference in the image data set also leads to a dissimilar manner in which airway measurements were obtained. Airways in the present data set were connected and parent generations distinguished by distal branching of child conduit vessels. Airway dimensions along the length of an airway were measured at each slice and output dimensions were representative of the average over the entire length of a given airway, rather from a single or a few select CT cross-sectional images.

Although previous studies were able to identify and analyze by hand smaller airways of unknown generation, these airways appear to have been examined and measured at discrete locations of the collected data set. Indeed, the largest airways reported in the study by King et al (airway size range, 0.9 to $4.0 \mathrm{~mm}$ in diameter) are comparable in size to the smallest interconnected airways segmented in the present study (airway size range, 4.0 to $14.3 \mathrm{~mm}$ in diameter). Thus, the findings of the present study may serve as a complement to those of this previous research study.

\section{Conclusions}

Rapid fluid loading increased lung tissue volume, induced pulmonary vascular engorgement, and caused restrictive and obstructive pulmonary function changes with some evidence of mild interstitial edema in healthy individuals. Generally, there were small alterations in the luminal areas and wall thicknesses of the airways that were reconstructed as part of the entire airway tree and delineated by noncontrast X-ray CT imaging techniques down to the fifth Weibel generation. These data suggest that changes in pulmonary function occurring with rapid fluid loading are not primarily mediated by changes in the larger airway, but may be determined by changes in smaller airways and vessels or resultant of changes in fluid volume of compartments that were not measured (eg, heart, great vessels, abdomen).

\section{Acknowledgments}

This study was supported by the National Institute of Health Grant HL71478 and Center for Translational Science Activities Grant Number 1 UL1 RR024150.

The authors would like to thank the subjects for their participation in our study; the important contributions of Minelle Hulsebus and Kathy O'Malley in the recruitment, consenting, and daily testing; and the staff of the Center for Translational Science Activities Clinical Research Unit for their expert help. We would also like to thank Dr. Robert Hyatt for his input regarding this study as well as Dr. Eric Hoffman for his technical expertise.

\section{References}

1. Olson TP, Beck KC, Johnson JB, Johnson BD. Competition for intra-thoracic space reduces lung capacity in patients with chronic heart failure: a radiographic study. Chest 2006;130:164e-71e. [PubMed: 16840397]

2. Olson TP, Snyder EM, Johnson BD. Exercise-disordered breathing in chronic heart failure. Exercise Sport Sci Rev 2006;34:194e-201e.

3. Cotter G, Metra M, Milo-Cotter O, Dittrich HC, Gheorghiade M. Fluid overload in acute heart failure —re-distribution and other mechanisms beyond fluid accumulation. Eur J Heart Fail 2008;10:165-9. [PubMed: 18279771] 
4. Olson TP, Beck KC, Johnson BD. Pulmonary function changes associated with cardiomegaly in chronic heart failure. J Card Fail 2007;13:100-7. [PubMed: 17395049]

5. Agostoni P, Marenzi G, Lauri G, Perego G, Schianni M, Sganzerla P, et al. Sustained improvement in functional capacity after removal of blody fluid with isolated ultrafiltration in chronic insufficiency: Failure of Furosemide to provide the same result. Am J Med 1994;96:191-9. [PubMed: 8154506]

6. Cabanes L, Costes F, Weber S, Regnard J, Benvenuti C, Castaigne A, et al. Improvement in exercise performance by inhalation of methoxamine in patients with impaired left ventricular function. $\mathrm{N}$ Engl J Med 1992;326:1661-5. [PubMed: 1588979]

7. Puri S, Dutka DP, Baker BL, Hughes JM, Cleland JG. Acute saline infusion reduces alveolar-capillary membrane conductance and increases airflow obstruction in patients with left ventricular dysfunction. Circulation 1999;99:1190-6. [PubMed: 10069787]

8. Farney RJ, Morris AH, Gardner RM, Armstrong JD Jr. Rebreathing pulmonary capillary and tissue volume in normals after saline infusion. J Appl Physiol 1977;43:246-53. [PubMed: 893278]

9. Guazzi M, Agostoni P, Bussotti M, Guazzi MD. Impeded alveolar-capillary gas transfer with saline infusion in heart failure. Hypertension 1999;34:1202-7. [PubMed: 10601119]

10. King LS, Nielsen S, Agre P, Brown RH. Decreased pulmonary vascular permeability in aquaporin-1null humans. Proc Natl Acad Sci U S A 2002;99:1059-63. [PubMed: 11773634]

11. Pellegrino R, Dellaca R, Macklem PT, Aliverti A, Bertini S, Lotti P, et al. Effects of rapid saline infusion on lung mechanics and airway responsiveness in humans. J Appl Physiol 2003;95:728-34. [PubMed: 12730149]

12. Robertson HT, Pellegrino R, Pini D, Oreglia J, DeVita S, Brusasco V, et al. Exercise response after rapid intravenous infusion of saline in healthy humans. J Appl Physiol 2004;97:697-703. [PubMed: 15090479]

13. Snyder EM, Beck KC, Turner ST, Hoffman EA, Joyner MJ, Johnson BD. Genetic variation of the beta2-adrenergic receptor is associated with differences in lung fluid accumulation in humans. J Appl Physiol 2007;102:2172-8. [PubMed: 17347382]

14. Ramchandani R, Shen X, Elmsley CL, Ambrosius WT, Gunst SJ, Tepper RS. Differences in airway structure in immature and mature rabbits. J Appl Physiol 2000;89:1310-6. [PubMed: 11007563]

15. Sera T, Fujioka H, Yokota H, Makinouchi A, Himeno R, Schroter RC, et al. Localized compliance of small airways in excised rat lungs using microfocal X-ray computed tomography. J Appl Physiol 2004;96:1665-73. [PubMed: 14766787]

16. Muir AL, Flenley DC, Kirby BJ, Sudlow MF, Guyatt AR, Brash HM. Cardiorespiratory effects of rapid saline infusion in normal man. J Appl Physiol 1975;38:786-93. [PubMed: 236273]

17. Brown RH, Zerhouni EA, Mitzner W. Visualization of airway obstruction in vivo during pulmonary vascular engorgement and edema. J Appl Physiol 1995;78:1070-8. [PubMed: 7775300]

18. Brown RH, Pearse DB, Pyrgos G, Liu MC, Togias A, Permutt S. The structural basis of airways hyperresponsiveness in asthma. J Appl Physiol 2006;101:30-9. [PubMed: 16469934]

19. Miller MR, Hankinson J, Brusasco V, Burgos F, Casaburi R, Coates A, et al. Standardisation of spirometry. Eur Respir J 2005;26:319-38. [PubMed: 16055882]

20. Tamhane RM, Johnson RL Jr, Hsia CC. Pulmonary membrane diffusing capacity and capillary blood volume measured during exercise from nitric oxide uptake. Chest 2001;120:1850-6. [PubMed: 11742912]

21. Roughton FJ, Forster RE. Relative importance of diffusion and chemical reaction rates in determining rate of exchange of gases in the human lung, with special reference to true diffusing capacity of pulmonary membrane and volume of blood in the lung capillaries. J Appl Physiol 1957;11:290-302. [PubMed: 13475180]

22. Meyer M, Schuster KD, Schulz H, Mohr M, Piiper J. Pulmonary diffusing capacities for nitric oxide and carbon monoxide determined by rebreathing in dogs. J Appl Physiol 1990;68:2344-57. [PubMed: 2384415]

23. Morris NR, Snyder EM, Beck KC, Haseler LJ, Olson LJ, Johnson BD. The relationship between resting lung-to-lung circulation time and peak exercise capacity in chronic heart failure patients. $\mathrm{J}$ Card Fail 2007;13:389-94. [PubMed: 17602986] 
24. Snyder EM, Beck KC, Hulsebus ML, Breen JF, Hoffman EA, Johnson BD. Short-term hypoxic exposure at rest and during exercise reduces lung water in healthy humans. J Appl Physiol 2006;101:1623-32. [PubMed: 16902060]

25. Hoffman EA, Sinak LJ, Robb RA, Ritman EL. Noninvasive quantitative imaging of shape and volume of lungs. J Appl Physiol 1983;54:1414-21. [PubMed: 6863100]

26. Brown RH, Mitzner W. Effect of lung inflation and airway muscle tone on airway diameter in vivo. J Appl Physiol 1996;80:1581-8. [PubMed: 8727543]

27. Wood SA, Zerhouni EA, Hoford JD, Hoffman EA, Mitzner W. Measurement of three-dimensional lung tree structures by using computed tomography. J Appl Physiol 1995:791687-97.

28. Kang, L. Efficient optimal net surface detection for image segmentation-from theory to practice. Iowa City, IA: University of Iowa; 2003.

29. Hu S, Hoffman EA, Reinhardt JM. Automatic lung segmentation for accurate quantitation of volumetric X-ray CT images. IEEE Trans Med Imaging 2001;20:490-8. [PubMed: 11437109]

30. Aykac D, Hoffman EA, McLennan G, Reinhardt JM. Segmentation and analysis of the human airway tree from three-dimensional X-ray CT images. IEEE Trans Med Imaging 2003;22:940-50. [PubMed: 12906248]

31. Saba OI, Hoffman EA, Reinhardt JM. Maximizing quantitative accuracy of lung airway lumen and wall measures obtained from X-ray CT imaging. J Appl Physiol 2003;95:1063-75. [PubMed: 12754180]

32. Tschirren J, Hoffman EA, McLennan G, Sonka M. Segmentation and quantitative analysis of intrathoracic airway trees from computed tomography images. Proc Am Thorac Soc 2005;2:484-7. 503-4. [PubMed: 16352753]

33. Tawhai MH, Burrowes KS, Hoffman EA. Computational models of structure-function relationships in the pulmonary circulation and their validation. Exp Physiol 2006;91:285-93. [PubMed: 16407477]

34. Robb RA, Hanson DP, Karwoski RA, Larson AG, Workman EL, Stacy MC. Analyze: a comprehensive, operator-interactive software package for multidimensional medical image display and analysis. Comput Med Imaging Graph 1989;13:433-54. [PubMed: 2688869]

35. Hyatt RE. Expiratory flow limitation. J Appl Physiol 1983;55:1-7. [PubMed: 6350246] 


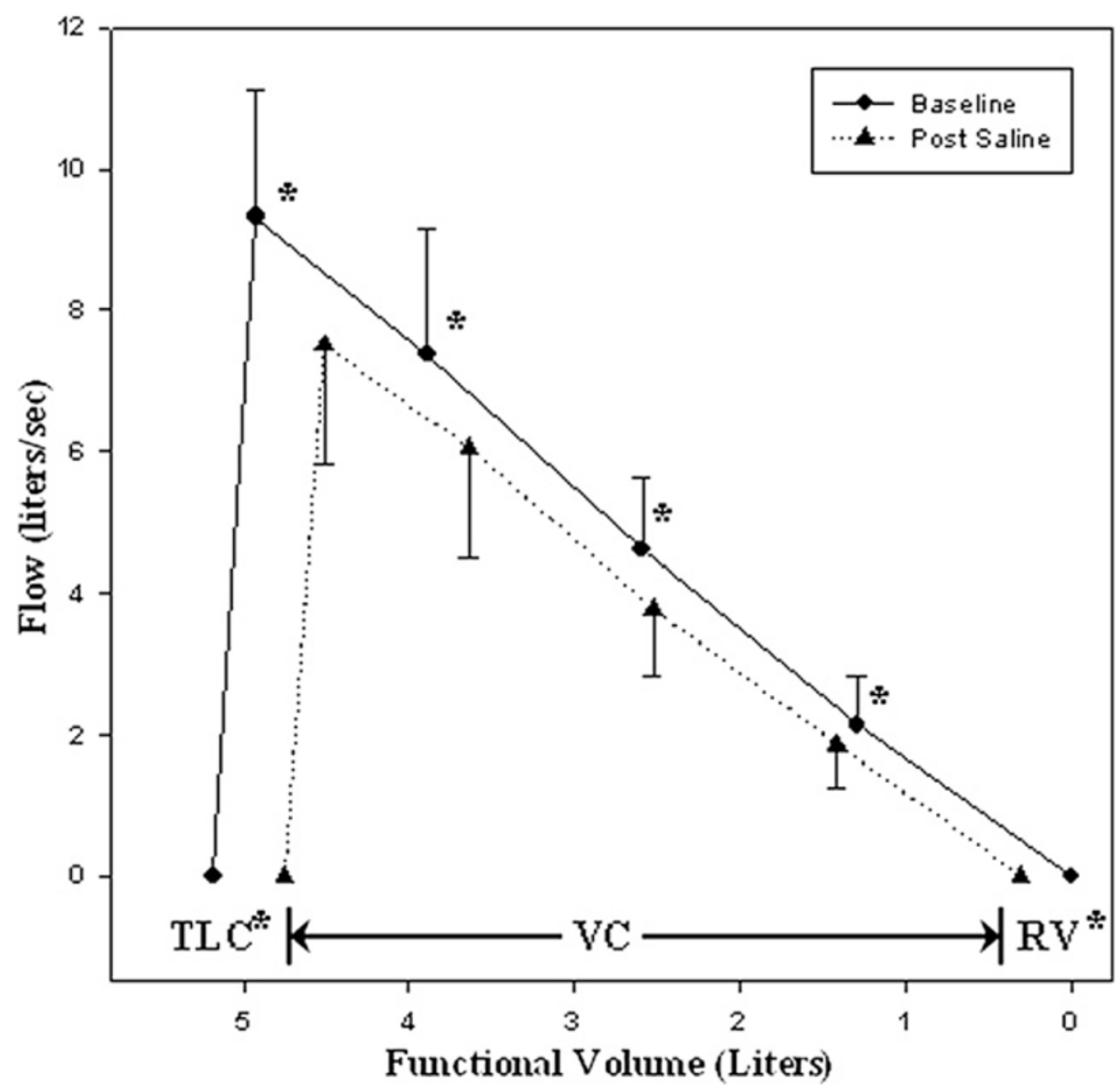

Fig. 1.

Mean maximal expiratory flow-volume (MEFV) envelope at baseline and postfluid loading. Average values of flow-volume measurements for all subjects $(n=16)$ collected at baseline (solid line) and after rapid fluid loading (dashed line). Of note are the parallel shift of the MEFV curve, the decrease in total lung capacity (TLC) and vital capacity (VC), and the increase in residual volume $(\mathrm{RV})$ that are observed postfluid loading. 
A

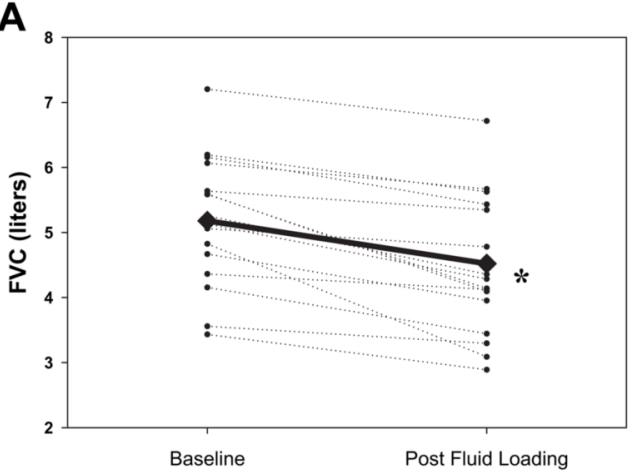

B

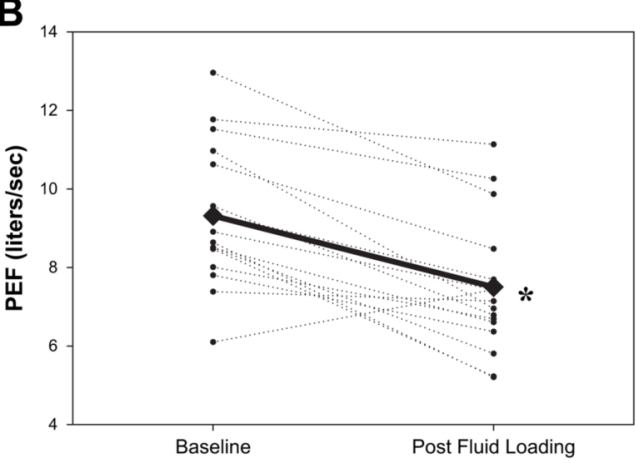

Fig. 2.

Baseline and postfluid loading changes in forced vital capacity (FVC) and peak expiratory flow (PEF). Measurements of FVC (A) and PEF (B) are shown for each individual (thin, dashed lines), and as an average for the entire group (thick, solid line). All individuals, except 1 , showed a decrease in both FVC and PEF in the postfluid loaded condition. 
A

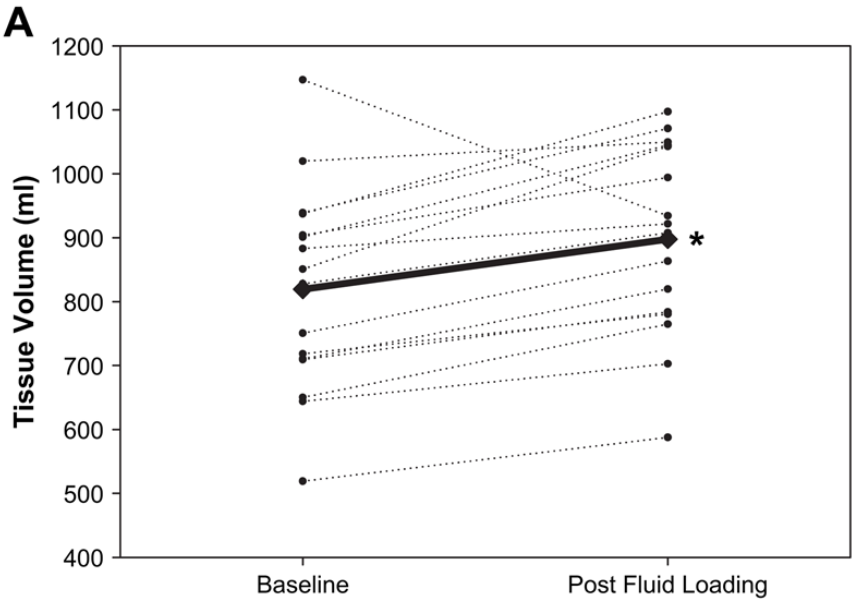

C

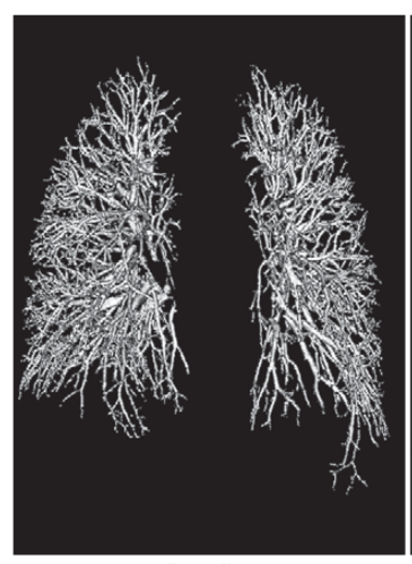

Baseline

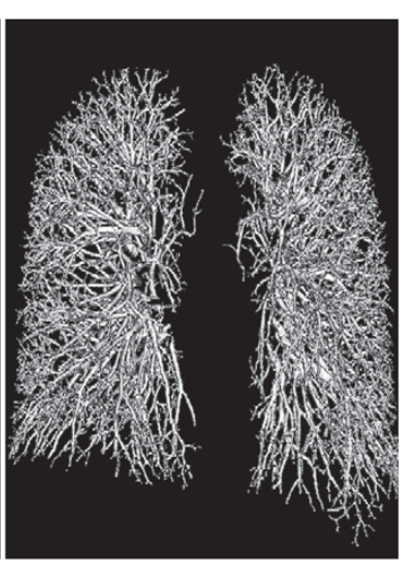

Post Fluid Loading
B

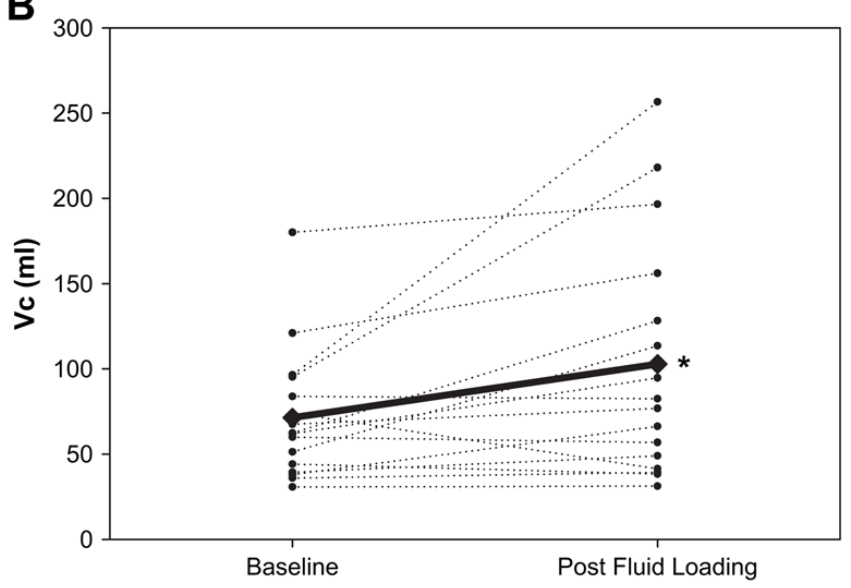

D

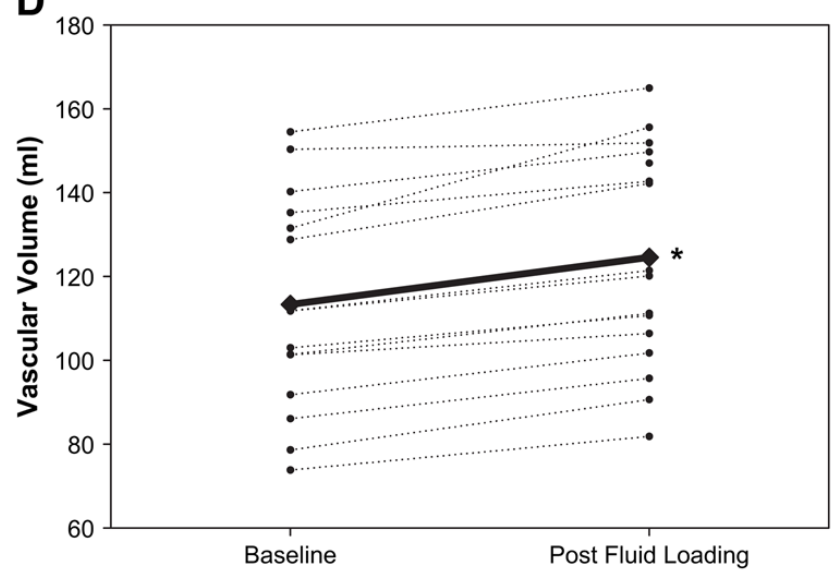

Fig. 3.

Distribution of fluid within various intrathoracic compartments at baseline and postfluid loading. Measurements of total lung tissue volume (A, computed tomography [CT] imaging methods), pulmonary capillary blood volume (B, soluble gas rebreathe methods), and segmented vascular volume (C and D, CT imaging methods) are shown for each individual (thin, dashed lines) and as an average for the entire group (thick, solid lines). All individuals, except 1 , displayed an increase in lung tissue volume and pulmonary capillary blood volume $\left(\mathrm{V}_{\mathrm{C}}\right)$ in the postfluid loaded condition. The individual that displayed a decrease in lung tissue volume was the same individual that displayed the decrease in $V_{C}$. The segmented vascular volume was also shown to increase relative to baseline in the post fluid loaded condition and can be seen visually (C) as well as graphically (D). 
A

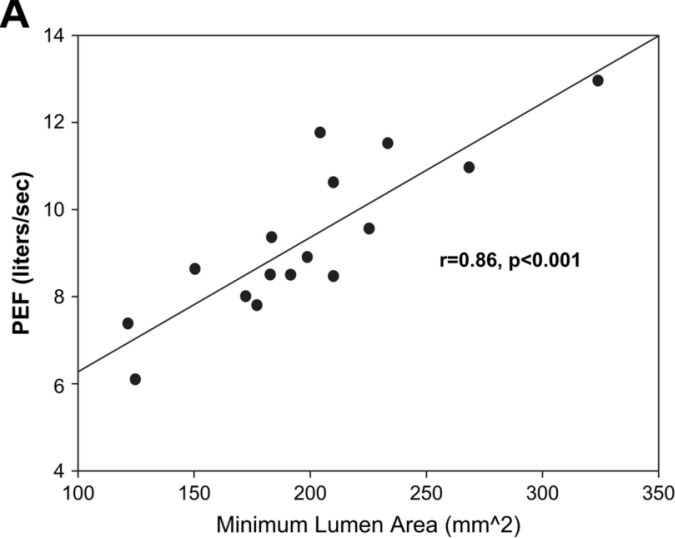

B

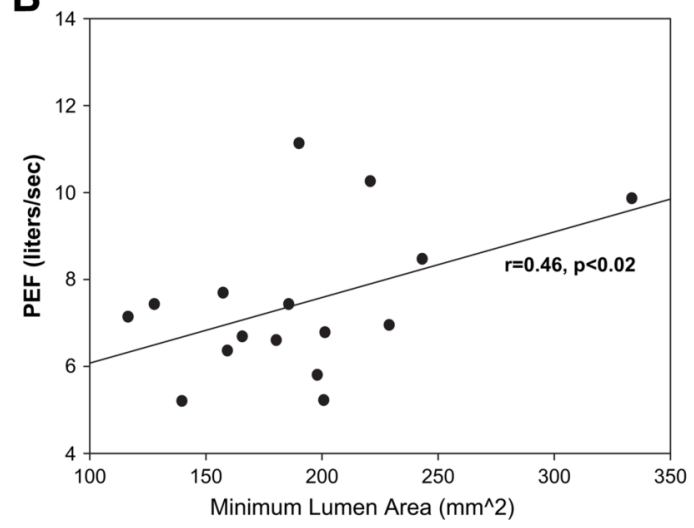

Fig. 4.

Baseline and postfluid loading structure function correlation. Correlation of the minimum lumen cross-sectional area of the trachea versus peak expiratory flow (PEF) at baseline (A) and after rapid fluid loading (B). At baseline, larger airways were well correlated with higher maximal flows. These correlations were significantly weakened or disappear entirely in the postfluid loaded state. 

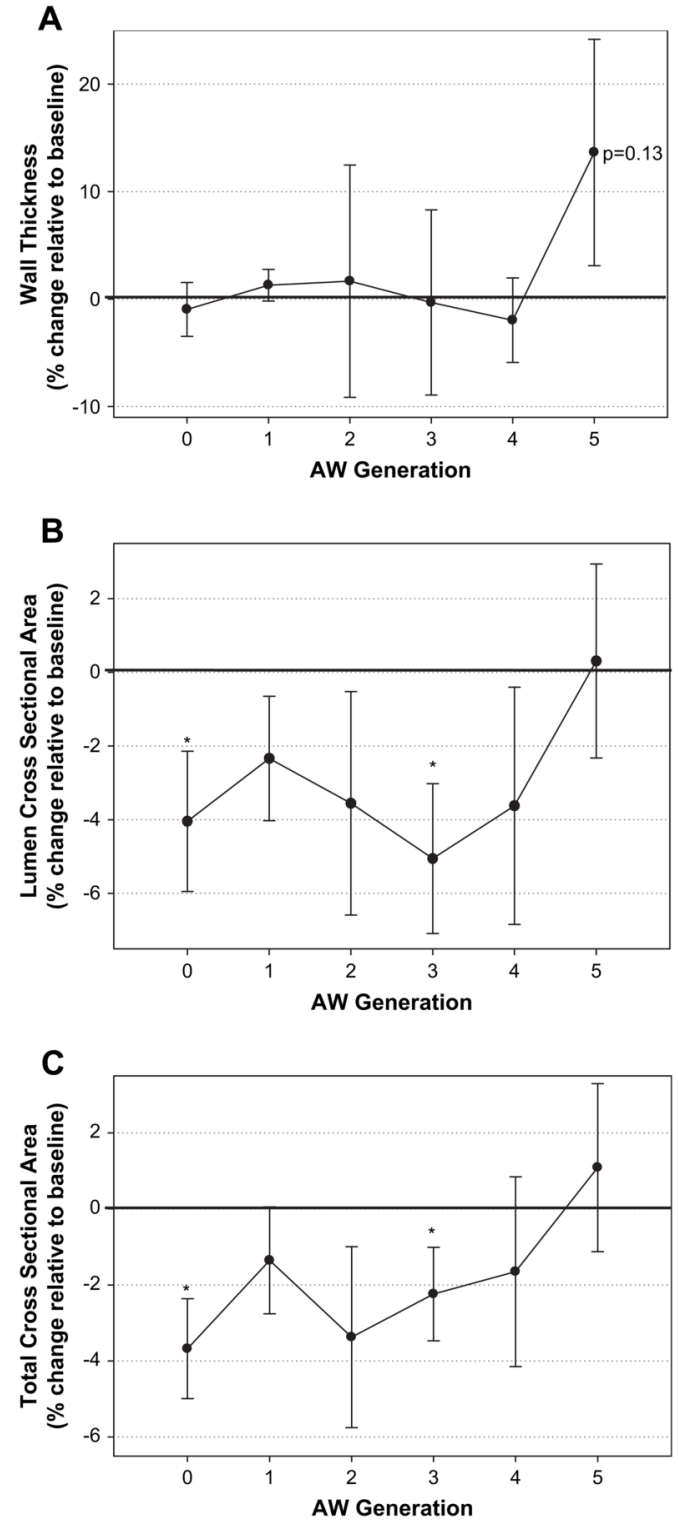

Fig. 5.

Percent changes in airway structure relative to baseline measurements according to airway generation. Average values of the percent change in airway wall thickness measurements (A), airway lumen cross sectional area measurements (B), and total airway cross-sectional area (C) relative to baseline values for all subjects according to airway generation (lumen + airway wall). Generations 0 to 4 comprised of 16 individuals, whereas generation 5 comprised 10 individuals. Significant changes in airway cross-sectional area were noted at generations 0 and 3. Airway wall thickness tended to increase at generation 5, although this change was not statistically significant. 


\section{Table 1}

Subject Characteristics

\begin{tabular}{lc}
\hline Characteristic & Mean \pm SD \\
\hline Sex (male/female) & $11 / 5$ \\
Age $(\mathrm{y})$ & $28.6 \pm 7.6$ \\
Height $(\mathrm{cm})$ & $174.6 \pm 8.3$ \\
Weight $(\mathrm{kg})$ & $73.7 \pm 11.3$ \\
Body mass index $\left(\mathrm{kg} / \mathrm{m}^{2}\right)$ & $24.1 \pm 2.8$ \\
Body surface area $\left(\mathrm{m}^{2}\right)$ & $1.9 \pm 0.2$ \\
\hline
\end{tabular}




\section{Table 2}

Subject Monitoring at Baseline and Postfluid Loading

\begin{tabular}{lcc}
\hline & Baseline & Postfluid Loading \\
\hline Heart rate $^{*}$, beats/min & $60 \pm 8$ & $73 \pm 14$ \\
Systolic blood pressure ${ }^{*}, \mathrm{~mm} \mathrm{Hg}$ & $112 \pm 9$ & $119 \pm 10$ \\
Diastolic blood pressure, mm Hg & $76 \pm 7$ & $75 \pm 8$ \\
Mean arterial pressure, mm Hg & $88 \pm 6$ & $90 \pm 6$ \\
$\% \mathrm{O}_{2}$ saturation & $97 \pm 1$ & $98 \pm 2$ \\
Cardiac output ${ }^{*}, \mathrm{~L} / \mathrm{min}$ & $4.1 \pm 0.8$ & $5.2 \pm 1.2$ \\
Stroke volume, mL & $69 \pm 18$ & $73 \pm 19$ \\
Chest tightness ${ }^{*}$ (scale of 0-4) & $0 \pm 0$ & $1.1 \pm 1.0$ \\
Intravenous saline infusion volume, $\mathrm{mL}$ & & $2201 \pm 344$ \\
Intravenous saline infusion time, min & & $20.5 \pm 2.1$ \\
\hline
\end{tabular}

Values are reported as mean \pm standard deviation.

* Paired $t$-test baseline vs. fluid loading $P<.001$. 
Table 3

Pulmonary Function/CT Scan Lung Volumes (Baseline and Postfluid Loading)

\begin{tabular}{|c|c|c|c|c|}
\hline & Baseline & Postfluid Loading & $\%$ Change & $P$ Value \\
\hline $\mathrm{FVC}^{\dagger}, \mathrm{L} \%$ predicted & $\begin{array}{l}5.2 \pm 1.0 \\
95 \pm 31\end{array}$ & $\begin{array}{c}4.5 \pm 1.1 \\
81 \pm 27\end{array}$ & $-14 \pm 9$ & $<.001$ \\
\hline $\mathrm{PEF}^{\dagger}, \mathrm{L} / \mathrm{s} \%$ predicted & $\begin{array}{l}9.3 \pm 1.8 \\
107 \pm 27\end{array}$ & $\begin{array}{l}7.4 \pm 1.7 \\
84 \pm 26\end{array}$ & $-19 \pm 15$ & $<.001$ \\
\hline $\mathrm{FEV}_{1}^{\dagger}, \mathrm{L} \%$ predicted & $\begin{array}{c}4.2 \pm 0.9 \\
94 \pm 30\end{array}$ & $\begin{array}{l}3.6 \pm 0.9 \\
78 \pm 26\end{array}$ & $-16 \pm 10$ & $<.001$ \\
\hline $\mathrm{FEV}_{1}, \mathrm{FVC}$ ratio \%predicted & $\begin{array}{l}0.82 \pm 0.03 \\
98 \pm 4\end{array}$ & $\begin{array}{l}0.80 \pm 0.06 \\
97 \pm 7\end{array}$ & $-2 \pm 5$ & .093 \\
\hline $\mathrm{FEF}_{25^{\dagger}}^{\dagger}, \mathrm{L} / \mathrm{s} \%$ predicted & $\begin{array}{l}7.4 \pm 1.8 \\
91 \pm 29\end{array}$ & $\begin{array}{l}6.1 \pm 1.6 \\
75 \pm 25\end{array}$ & $-17 \pm 13$ & $<.001$ \\
\hline $\mathrm{FEF}_{50}{ }^{\dagger}, \mathrm{L} / \mathrm{s} \%$ predicted & $\begin{array}{l}4.6 \pm 1.0 \\
90 \pm 24\end{array}$ & $\begin{array}{l}3.8 \pm 1.0 \\
74 \pm 23\end{array}$ & $-18 \pm 14$ & $<.001$ \\
\hline $\mathrm{FEF}_{75}{ }^{*}, \mathrm{~L} / \mathrm{s} \%$ predicted & $\begin{array}{l}2.1 \pm 0.7 \\
95 \pm 33\end{array}$ & $\begin{array}{l}1.8 \pm 0.6 \\
83 \pm 30\end{array}$ & $-11 \pm 23$ & .010 \\
\hline $\mathrm{FEF}_{25-75}{ }^{*}, \mathrm{~L} / \mathrm{s} \%$ predicted & $\begin{array}{l}4.1 \pm 1.0 \\
101 \pm 29\end{array}$ & $\begin{array}{l}3.4 \pm 1.0 \\
82 \pm 26\end{array}$ & $-15 \pm 20$ & .002 \\
\hline $\mathrm{TLC}^{*}, \mathrm{~L}$ & $6.8 \pm 1.2$ & $6.4 \pm 2.0$ & $-6 \pm 8$ & .008 \\
\hline $\mathrm{IC}^{*}, \mathrm{~L}$ & $3.4 \pm 0.6$ & $3.1 \pm 0.7$ & $-7 \pm 14$ & .039 \\
\hline $\mathrm{RV}^{*}, \mathrm{~L}$ & $1.6 \pm 0.7$ & $2.0 \pm 0.8$ & $38 \pm 56$ & .003 \\
\hline
\end{tabular}

FVC, forced vital capacity; PEF, peak expiratory flow; FEV 1 , forced expiratory volume in $1 \mathrm{~s} ; \mathrm{FEF}_{25}$, FEF50, and FEF75, forced expiratory flow at $25 \%, 50 \%$, and $75 \%$ of $\mathrm{FVC}$, respectively; $\mathrm{FEF}_{25}-75$, maximum mid-expiratory flow; IC, inspiratory capacity.

Values are reported as mean $\pm \mathrm{SD}$.

Paired $t$-test of baseline vs. postfluid loading $P<.05$.

${ }^{\dagger}$ Paired $t$-test of baseline vs. postfluid loading $P<.001$. 
Table 4

Fluid Distribution within the Lung (Baseline and Postfluid Loading)

\begin{tabular}{|c|c|c|c|c|}
\hline & Baseline & Postfluid Loading & $\%$ Change & $P$ Value \\
\hline Diffusing capacity for carbon monoxide $\left(\mathrm{D}_{\mathrm{LCO}}\right)^{*}$ & $25.5 \pm 4.6$ & $23.8 \pm 4.5$ & $-6 \pm 9$ & .008 \\
\hline Membrane diffusing capacity $\left(D_{M}\right)^{*}$ & $33.7 \pm 8.1$ & $30.7 \pm 9.0$ & $-9 \pm 15$ & .019 \\
\hline Capillary blood volume $\left(\mathrm{V}_{\mathrm{C}}\right)^{*}, \mathrm{~mL}$ & $71.3 \pm 38.4$ & $102.8 \pm 70.2$ & $42 \pm 60$ & .012 \\
\hline $\mathrm{D}_{\mathrm{M}} / \mathrm{V}_{\mathrm{C}}$ ratio ${ }^{*}$ & $0.6 \pm 0.3$ & $0.5 \pm 0.4$ & $-23 \pm 38$ & .035 \\
\hline Lung tissue volume ${ }^{*}, \mathrm{~mL}$ & $819 \pm 160$ & $898 \pm 149$ & $10.5 \pm 9.2$ & .002 \\
\hline Total lung volume ${ }^{*}, \mathrm{~mL}$ & $3963 \pm 894$ & $4038 \pm 884$ & $2.1 \pm 2.4$ & .010 \\
\hline Segmented vascular volume ${ }^{\dagger}, \mathrm{mL}$ & $113 \pm 26$ & $125 \pm 26$ & $9 \pm 4$ & $<.001$ \\
\hline
\end{tabular}

Measures of diffusing capacity for carbon monoxide ( $\mathrm{D}_{\mathrm{LCO}}$ ), membrane diffusing capacity $\left(\mathrm{D}_{\mathrm{M}}\right)$, capillary blood volume $\left(\mathrm{V}_{\mathrm{C}}\right)$, and $\mathrm{D}_{\mathrm{M}} / \mathrm{V}_{\mathrm{C}}$ were obtained by soluble gas methods. Lung tissue volume, total lung volume, and segmented vascular volume were obtained from x-ray computed tomography imaging.

Paired $t$-test of baseline vs. post fluid loading $P<0.05$.

${ }^{\dagger}$ Paired $t$-test of baseline vs. post fluid loading $P<0.001$. 